\title{
O que escuta o clínico/fonoaudiólogo frente à fala jargonafásica?
}

\section{What does the clinician/speech therapist listen to in the face of the jargon-aphasic speech?}

\author{
Michelly Daiane de Souza Gaspar Cordeiro ${ }^{1}$ \\ Maria Francisca de Andrade Ferreira Lier-DeVitto ${ }^{2}$ \\ Juliana Ferreira Marcolino-Galli ${ }^{3}$ \\ Melissa Catrini da Silva 4
}

DOI: $10.28998 / 2317-9945.2019 n 63 p 192-206$

\begin{abstract}
Resumo
Este trabalho problematiza a natureza da fala jargonafásica, a partir de uma aproximação à Linguistica Estruturalista (Saussure e Jakobson) e à Psicanálise, que tem no cerne a interpretação da relação sujeitolinguagem (lingua e fala), como proposto pelo Interacionismo (DE LEMOS, 1992, 1997, 2002) e a Clinica de Linguagem (LIER-DeVITTO, 2000; ARANTES, 2001 e outros). Realizou-se uma análise linguistica de dados de fala jargonafásica retirados da literatura fonoaudiológica. Neles, destacou-se a importância de um refinamento teórico-clínico necessário para a construção de uma escuta singular, que se afaste de métodos cientificos de descrição e classificação. Foi abordado o funcionamento linguístico particular que comanda a fala afásica e seus efeitos no sujeito. A discussão perpassa, ainda, uma reflexão sobre a escuta do afásico e a interpretação do clínico.
\end{abstract}

Palavras-chave: Jargonafasia. Linguagem. Escuta

\section{Abstract}

This work proposes a problematization of the nature of jargon-aphasic speech, based on Structuralist Linguistics (Saussure and Jakobson) and Psychoanalysis, whose core is the interpretation of the subjectlanguage relationship (language and speech), as proposed by Interacionism (DE LEMOS, 1992, 1997, 2002) and the Language Clinic (LIER-DeVITTO, 2000; ARANTES, 2001 and others). A linguistic analysis of jargon-aphasic speech was performed using the data from the speech-language literature. In the analysis of this data, it was emphasized the importance of a theoretical-clinical refinement necessary to the construction of a singular listening, different from scientific methods of description and classification. It was approached the specific linguistic mechanism that is responsible for the aphasic speech and its effects on the subject. It is also part of the discussion a reflection regarding the listening of the aphasic and the interpretation of the clinician.

Keywords: Jargon aphasia. Language. Listening

Recebido em: 15/08/2018.

Aceito em: 19/09/2018.

\footnotetext{
${ }^{1}$ Mestre em Linguística Aplicada e Estudos da Linguagem pela Pontifícia Universidade Católica de São Paulo. Professora Substituta no Departamento de Fonoaudiologia da Universidade Estadual do Centro-Oeste.

2 Doutora em Linguística pela Universidade Estadual de Campinas. Professora titular da Pontifícia Universidade Católica de São Paulo.

${ }^{3}$ Doutora em Linguística Aplicada e Estudos da Linguagem pela Pontifícia Universidade Católica de São Paulo. Professora adjunta da Universidade Estadual do Centro-Oeste.

${ }^{4}$ Doutora em Linguística Aplicada e Estudos da Linguagem pela Pontifícia Universidade Católica de São Paulo. Professora adjunta da Universidade Federal da Bahia.
} 


\section{Introdução}

$\mathrm{Na}$ literatura médica e fonoaudiológica, é frequente a descrição da fala afásica circunscrita em classificações que elencam sinais, descritos como jargões, neologismos, parafasias, agramatismos, circunlóquios, estereotipias, anomias, entre outros. A jargonafasia é uma das nomenclaturas utilizadas para descrever a fala e/ou escrita repleta de neologismos $^{5}$ (ORTIZ, 2010). Diferentes autores, atravessados por divergentes posições teóricas, discutem a dificuldade em definir e explicar a jargonafasia como uma categoria clínica específica (MARCOLINO, 2009; OLIVEIRA, MARCOLINO, 2009; TUBERO, 2010; ISHARA, 2010; CORDEIRO, MARCOLINO-GALLI, LIER-DeVITTO, 2013).

Vale destacar que não há consenso na literatura a respeito da distinção entre jargonafasia e falas afásicas com outras características sintomáticas, tampouco uma discussão que problematize a natureza dessa manifestação linguística. Para sustentar essa afirmação é pertinente um percurso breve por alguns autores. Butterworth (1979) teorizou que a afasia com jargões é uma fala/discurso mais ou menos inteligível, fluente ou super fluente, com parafasias, circunlóquios e neologismos. Brown (1981) definiu a jargonafasia como uma fala repleta de sons sem significado. Nessas duas definições podemos observar distância de um discurso linguístico sobre a fala, e, também, uma definição ampla que poderia descrever diversas falas afásicas, inclusive inserindo outros sinais que caracterizam a fala com jargões. Outras definições vigentes no campo da afasiologia são baseadas na proposição de Alajouanine que, em 1952, afirmou que a afasia com jargão corresponde à "desintegração anosognósica ${ }^{6}$ dos valores semânticos da linguagem" (KINSBOURNE; WARRINGTON, 1963, p. 36), o que acarreta na produção de não-palavras que podem ser denominadas neologismos. Definição semelhante foi proposta por Butterworth (1979). Parece ser a partir dessa última proposição que se fundamentam as definições de jargonafasia como dificuldade de percepção e reconhecimento dos processos fonológicos no acesso lexical e semântico de uma língua (ISHARA, 2004). Notam-se que as definições sobre a fala jargonafásica, presentes em trabalhos iniciais, ressoam atualmente.

De maneira geral, além das tentativas de definição terminológica, observam-se na literatura fonoaudiológica proposições de metodologias distintas para analisar as falas jargonafásicas. Por exemplo, na perspectiva da Neuropsicologia Cognitiva, a análise dessas falas é realizada a partir de tarefas cognitivas de nomeação de palavras e figuras, repetição, testes semânticos e fonológicos, entre outras atividades metalinguísticas (BOSE, 2013). Nesses trabalhos, a fala espontânea é apenas mencionada e a avaliação é abordada em um viés quantitativo. Já na Neurolinguística Discursiva, por outro aporte teórico, os dados são considerados em uma análise qualitativa dos eventos dialógicos. As explicações permeiam a questão das possibilidades discursivas nas falas jargonafásicas e recorrem ao processamento cognitivo de níveis fonético-fonológico, lexical, semântico e pragmático para analisar os déficits nessas falas (COUDRY, 2003; ISHARA, 2003).

A questão é que essa terminologia e aproximação à jargonafasia não é suficiente para uma análise linguística da fala, pois somente auxilia o investigador a enquadrar a fala afásica em um quadro nosológico específico ou ditar processadores alterados, e nada diz do funcionamento singular e subjetivo de um falante afásico. Desse modo, justifica-se a importância deste trabalho em oferecer uma visão alternativa para explicar a jargonafasia sob um olhar linguístico, ao se aproximar de dados de falas.

\footnotetext{
${ }^{5}$ Definidos como sequências fonêmicas ou grafêmicas que não fazem parte da língua e parecem palavras, mas não estão no dicionário nem são reconhecidas pelos falantes (ORTIZ, 2010).

${ }^{6}$ Falta de consciência da própria doença, o que dificulta o automonitoramento (BUTTERWORTH, 1979).
} 
Sendo assim, a posição teórica privilegiada nesse artigo prioriza a relação sujeitolinguagem, ao sublinhar a impossibilidade de descrição das diferentes manifestações de fala afásica. Este artigo filia-se à perspectiva teórica denominada Clínica de Linguagem, a partir dos pressupostos teóricos encaminhados das discussões no projeto de pesquisa "Aquisição, Patologias e Clínica de Linguagem" no LAEL - PUC/SP ${ }^{7}$. Essas discussões se aproximam, com diferença, à Linguística Estruturalista (Saussure e Jakobson), à proposta interacionista de C. de Lemos $(1992,1997)$ na área de Aquisição da Linguagem e à Psicanálise, por se tratar de uma clínica e também por conceber o sujeito do inconsciente, compatível com o conceito saussuriano de Língua (DE LEMOS, 1997).

Fonseca $(1995,2002,2011)$ é uma autora filiada à Clínica de Linguagem e foi pioneira nas discussões sobre afasia. Ela afirma que a afasia é fala em sofrimento que implica um "drama subjetivo" (FONSECA, 2002) - ponto importante porque ela nos desloca para a esfera da clínica, em que é o sofrimento de um sujeito que o movimenta e pede uma ação clínica. Dito de outro modo, uma das particularidades da vertente teórica assumida é discutir a fala sintomática (afásica), sem esquecer que ela é recolhida na clínica. Assim, não se discute a fala como "dado" em sentido estrito, mas como "material clínico". Neste caso, a relação sujeito-fala é ponto de partida, inclusive para a discussão da fala que promove sofrimento, um efeito na escuta do sujeito. Ficamos frente, assim, à impossibilidade de sustentar uma "abordagem da jargonafasia", per se, como uma categoria universalizada, regularizada. Isso porque a relação de um sujeito com sua fala é, sempre, singular (não há dois casos iguais, nem a manifestação de uma fala é homogênea à outra).

O objetivo deste trabalho é problematizar a natureza das falas ditas jargonafásicas, no cenário teórico e, por efeito no cenário clínico, destacando um olhar para falas em pleno funcionamento, para além de um viés descritivo. Para tanto, realizou-se uma análise linguística de dados descritos na literatura com objetivo de oferecer uma reinterpretação para esses enunciados, sob o viés da Clínica de Linguagem. Além disso, conceitos clínicos como escuta e interpretação ganham destaque no decorrer da discussão, a qual propicia questões sobre se haveria diferença para o fonoaudiólogo na clínica de linguagem frente a pacientes afásicos com e sem a manifestação jargonafásica em suas falas.

\section{Metodologia}

Trata-se de análise qualitativa, envolvendo recortes de situações clínicas retiradas da literatura, cuja seleção privilegiou enunciados afásicos com fala jargonafásica. Realizou-se revisão bibliográfica nas bases de pesquisa Scielo, Lilacs e Google Acadêmico com o descritor jargonafasia. Foram selecionados apenas artigos científicos que incluíssem em sua discussão análise de falas jargonafásicas. Destaca-se a escassez da literatura com discussão e análise dessas falas. A partir dessa seleção inicial foi realizada a leitura dos artigos e foram selecionados dois recortes de dados (enunciados de afásicos descritos na literatura como falantes jargonafásicos). Portanto, a escolha desses dados foi apoiada unicamente nos artigos selecionados que incluíram em seus trabalhos análises de falas jargonafásicas. Vale destacar que os dois recortes selecionados foram discutidos em artigos que se baseiam em perspectivas teóricas diferentes, com análise distinta para as falas.

\footnotetext{
${ }^{7}$ Este projeto foi idealizado e coordenado por Maria Francisca Lier-DeVitto (1997) e tem Lúcia Arantes como vice-líder desde 2002.
} 
Esses enunciados foram reanalisados com base nos movimentos metafórico e metonímico, processos que foram ressignificados por Jakobson (1988), a partir dos eixos sintagmático e associativo propostos por Saussure (2012).

Importa destacar que a posição do investigador frente ao material seguiu a proposta de Carvalho $(1995,2005,2006)$, autora filiada ao Interacionismo na área de Aquisição da Linguagem. Ela questiona o saber científico e a posição do investigador que toma distância do seu objeto. A partir de Milner (2012), Carvalho ressalta que o investigador é sujeito falante e que, ao estudar sua própria língua, sofre a imposição de um retorno sobre si, o que deixa ver sua subjetividade. A proposta da autora é a suspensão do significado e do saber prévio para que o investigador se surpreenda com o material, permitindo se afetar por um estranhamento de caráter enigmático, guiado pela primazia do significante. Frente a esse enigma, pela via do significante, o investigador opera a partir de movimentos de progressão e retroação, assim como nos ensinou Saussure (2012), Jakobson (1988) e Lacan $(1956,2010)$.

Esse olhar proposto por Carvalho foi fundamental na reinterpretação dos dados a partir da posição teórica já demarcada: a Clínica de Linguagem. Além disso, os dados selecionados abriram espaço para uma discussão sobre escuta e justificam o caminho teórico que será realizado no próximo item.

\section{Sobre a escuta no Interacionismo e na Clínica de Linguagem}

A escuta é conceito amplamente discutido na perspectiva da Clínica de Linguagem, sendo fundamental para o fazer clínico. Esse conceito foi despontado no campo da Aquisição de Linguagem, na proposta Interacionista de Cláudia de Lemos. Essa autora foi pioneira na discussão sobre escuta ao explicar a mudança na fala da criança a partir de posições estruturais (DE LEMOS, 1997, 2002). Como afirmou Andrade (2005), o pensamento instituído pela autora é uma ruptura a um viés instrumental e tradicional, abrindo espaço para uma teorização que articula sujeito, língua e fala com alicerces na Linguística Saussuriana e na Psicanálise.

Sendo assim, a proposição teórica, que desloca a apreensão da posição do falante para a "escuta para a fala" é o Interacionismo. De Lemos (1997) introduz a mudança na fala da criança na aquisição da linguagem como mudança de posição da criança na estrutura criança-língua-fala e então, reinterpreta a curva em U. Está curva representa a trajetória da criança na linguagem como um percurso, como uma sequência do tipo acerto-erro-acerto, e foi abordada por psicólogos cognitivistas ${ }^{8}$ (KARMILOFF-SMITH, 1986; PETERS, 1983). A reinterpretação que De Lemos (1997) propõe se afasta de uma visada cognitivista e/ou construtivista. A impossibilidade de descrever a fala indeterminada, assistemática e cambiante da criança, que oscila entre o que se supõe ser "acerto" ou "erro", leva a autora a se aproximar da ideia de "julgamento" em Chomsky e deslocar a reflexão e investigação mudança da fala para a escuta; esta, sim, capaz de apreender o movimento nada linear do sujeito na linguagem.

\footnotetext{
${ }^{8}$ Essa proposta pode ser encontrada em abordagens construtivistas, utilizada para explicar as mudanças na fala da criança em processo de aquisição; há em um momento a tomada de consciência, o período Ss, no qual emerge uma capacidade metalinguística na criança.
} 
Importante ressaltar que essas mudanças não são ações perceptivas ou cognitivas realizadas pela criança, num gesto de apropriação da linguagem como se ela fosse objeto de observação ou lugar da ação. A linguagem "acontece nela", diria Chomsky (1988, p. 134)". De Lemos (1997) sustenta, mais próxima da Psicanálise, que a criança é capturada pela linguagem. Assim, nesses dois pontos de vista, diferentes que são, fica afastada a hipótese cognitivista da Psicologia. Os tempos dessa captura passam por considerações sobre a escuta da criança a partir daquilo que acontece em sua fala e de como ela é afetada pela fala do outro e pela própria. Posições na estrutura criança-língua-fala serão postuladas e a "curva em U” será, por efeito disso, também ressignificada. Em um primeiro momento (aquele primeiro tempo dito de "acerto"), corresponde a um tempo de alienação à fala do outro - a criança fala fragmentos incorporados de enunciados produzidos no diálogo com ela - não há, portanto, escuta: ela é falada pelo outro. Ou seja: a criança fala a fala do outro. Já vemos, aqui, a natureza triádica da interação nesta proposta - a Língua está na fala do outro e garante o trânsito metonímico entre as falas. Em outro tempo, que não abole este, surgem os erros como indícios de afastamento da fala do outro - a criança, porém não se corrige e nem aceita correção. Os erros dizem da escuta e também da dominância da Língua em sua fala, que ganha extensão, sem coesão, contudo. Aparece, aqui, como afirma Lier-DeVitto, "a fala de criança" (não coincidente com a do adulto, mas movimentada pelas leis de referência interna da linguagem). Os paralelismos, estudados por Lier-DeVitto, são acontecimentos notáveis dessa segunda posição: neles há coesão estrutural e desarranjo de sentido. Digamos que a criança fala, mas não escuta o que fala. Por fim, propõe De Lemos, há o tempo da cisão entre fala e escuta (do sujeito falante/ouvinte), há possibilidade de saída da alienação fundante. Emergem reformulações e correções da fala de outros índices de escuta para a fala.

A noção de escuta e sua problematização foi um passo importante realizado por De Lemos. Retomando o que foi teorizado, a escuta é efeito do atravessamento da linguagem, ou ainda, do funcionamento da língua, e diz respeito à relação da criança com a sua própria fala e com a fala do outro (DE LEMOS, 1997, 2002). É esse movimento que abre espaço para emergência do sujeito, efeito da estruturação pela linguagem. Sendo assim, o sujeito é marcado por uma escuta que instaura uma posição na linguagem.

Sob efeito da filiação ao Interacionismo, a discussão sobre escuta foi também realizada no cenário da Clínica de Linguagem. Andrade (2003, 2005) teoriza sobre o estatuto da percepção na Fonoaudiologia, criticando com argumentos sólidos como a linguagem é descrita na qualidade de um objeto a ser conhecido via aparatos perceptuais. A autora destaca que ouvir e escutar não são equivalentes, como a própria língua registra a necessidade de distinguir os dois termos.

Arantes (1997) escreveu, a partir de Barthes, que ouvir é capacidade biológica/fisiológica e escutar envolve uma interpretação - envolve, portanto, a consideração de um corpo pulsional ${ }^{10}$, falado e falante. A questão é que há "impossível coincidência ou, melhor, necessária dissimetria entre ouvir e escutar" (ANDRADE, 2003, p. 133). Ela alerta para o fato de que uma Clínica Fonoaudiológica pode se assentar em uma dessas possibilidades, sendo: (1) vislumbrar o input da fala como acessível pela via sensorial, perceptual - aí, o clínico estaria do lado do ouvir; ou (2) implicar a relação línguafala-sujeito, que suspende a possibilidade da linguagem ser apreendida por aparatos

\footnotetext{
${ }^{9}$ Ver, sobre isso, Lier-DeVitto \& Fonseca (1997).

10 Essa expressão foi mencionada por Maria Tereza Lemos (2002) e por Cláudia de Lemos (2002), que qualificam corpo pulsional como aquele que "demanda interpretação, isto é, corpo que, articulado na e pela linguagem, se acha no regime da demanda e do desejo (DE LEMOS, 2002, p. 64).
} 
perceptuais e, sim e unicamente, pela via do corpo falado, corpo pulsional - aí o clínico coloca-se ao lado do escutar. Nesse caso, não há meia-medida, mesmo porque assumir uma posição depende do modo de captura do corpo do clínico por uma teoria (ou crença). Nessa captura, uma posição é definida, necessariamente (CARVALHO, 2006). De Lemos (2002) deixa claro que corpo pulsional é aquele interpretado pela linguagem, que só pode ser considerado a partir do simbólico. A Clínica de Linguagem assenta suas proposições teóricas e sua clínica segundo este olhar - linguagem e subjetivação, como destaca Lacan, articulam-se. A linguagem vem como condição de possibilidade de haver sujeito falante e inconsciente.

A partir dos trabalhos vinculados à Clínica de Linguagem, pode-se dizer que na fala afásica a língua (la langue) opera sem que o sujeito possa incidir sobre ela (FONSECA, 1995, 2002; MARCOLINO, 2004). Ainda que em falas outras, de crianças, por exemplo, a força desse funcionamento de la langue também seja constante, a diferença, no caso da afasia, reside no fato de que o afásico tem escuta para sua fala e sofre por isso. No caso de crianças, essa força constante pode se mostrar, mas o efeito na escuta da criança é outro. Ou seja, considera-se a posição do sujeito frente à própria fala e à fala do outro, ao assumir que a relação sujeito-linguagem inclui a cisão entre fala e escuta e seus efeitos.

Lier-DeVitto (1998, 2001), em seu trabalho sobre os monólogos, traz à luz a força da estrutura, do paralelismo, em que há projeção do eixo metafórico sobre o metonímico há predominância da função poética (JAKOBSON, 1988). Fato é que o paralelismo é dominante na poesia, assim como nos monólogos das crianças. $\mathrm{Na}$ poesia ou nos monólogos, o sujeito desliza na massa sonora, articulada pela rede simbólica. Acontece que paralelismos sustentam também falas afásicas, como é possível observar no segmento abaixo:

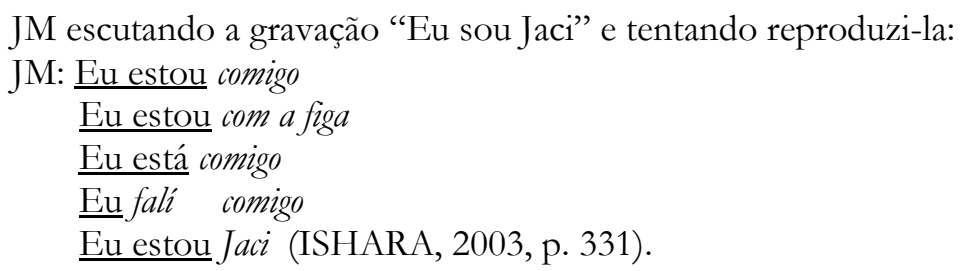

Chamamos a atenção para as palavras destacadas em negrito e itálico, compostas em um monta-remonta da massa sonora, articulada na estrutura: "Eu estou comigo", que garante a mobilidade alternada de seus elementos. Requer a atenção, de fato, a sequência paralelística do segmento acima, que, diferentemente das análises tradicionais, nos remete à interpretação de Lier-DeVitto (1998) dos monólogos da criança:

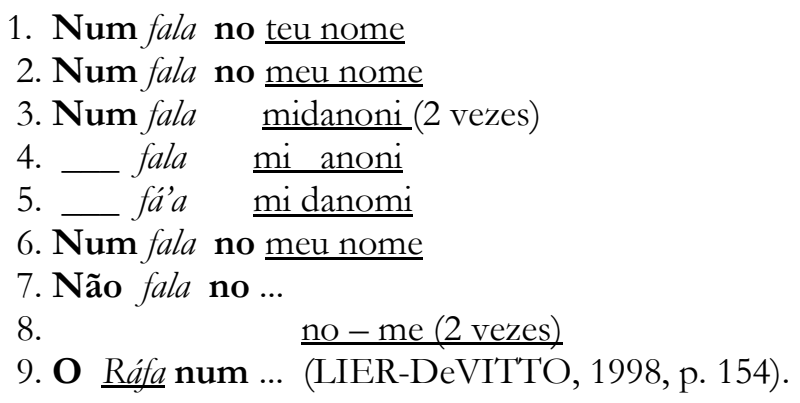

Interessa assinalar que tal aproximação ilumina o fato de que os enunciados afásicos, tanto quanto os de crianças, estão submetidos à estrutura e à mobilidade que a 
língua autoriza. Em sequências paralelísticas, aparece um movimento "metaforicamente metonímico", como mostrou Lier-DeVitto (1998), uma vez que as substituições acontecem "em presença" (e não "em ausência") - há língua em operação na fala afásica! Tal interpretação toma distância do raciocínio classificatório e gramatical e joga luz sobre a "força da organização significante", como nas montagens-desmontagens; articulações e rearticulações significantes, seja em falas de crianças, seja em falas afásicas: "o que nelas impõe é o funcionamento da língua" (LIER-DeVITTO; FONSECA, 1997, p. 68). Reiteramos, a diferença reside na posição do sujeito: o afásico escuta o que diz e sofre; a criança, nos monólogos estudados por Lier-DeVitto, não tem a escuta imaginária de um falante constituído e, por isso, não sofre por efeito de desarranjos em sua fala. É fundamental insistir que essa analogia: fala de crianças em aquisição e falas sintomáticas afásicas, embora possível, traz a necessidade de demarcar a indiscutível e radical diferença, afinal tratam-se de posições e relações diferentes com a linguagem.

Importa, para este artigo, lembrar que a ideia de estrutura proposta por De Lemos barra a ideia de cronologia e de estágio - pode-se falar em dominâncias, de privilégio de uma posição, não em sucessão ou superação de posições. Fato é que o discernimento da diferente posição da criança e do afásico na linguagem são fundamentais. $O$ afásico é falante constituído - e por efeito de uma lesão cerebral encontra-se em uma nova condição linguística. Portanto, pode-se afirmar que o afásico fica sob efeito de sua fala despedaçada, ele escuta e é afetado pela dissemelhança em relação a uma condição e aos outros falantes - ele sofre (FONSECA, 1995, 2002). Acontece, porém, que esta escuta não é ponto de apoio para mudanças na fala do afásico (LIER-DeVITTO; FONSECA, 2012). Escutar não é garantia para uma ação transformadora sobre a linguagem e nem é ela permanente - uma capacidade: a escuta tem intermitências.

\section{O caminho em direção às falas jargonafásicas: uma posição de escuta}

Alguns dados com fala jargonafásica parecem sustentar as afirmações feitas anteriormente sobre a escuta em afásicos. Os dois segmentos retirados da literatura fonoaudiológica pertencem a artigos divergentes, seja pela posição teórica ou pela análise realizada $^{11}$. Os dados serão reinterpretados nesta seção a partir dos movimentos metafóricos e metonímicos que apoiam uma análise linguística, bem como uma posição de escuta para o que imerge na fala desses sujeitos. Segue o primeiro segmento, com fala denominada jargonafásica:

1. IMC: Então vamos lá, vamos ler todo o texto, ó: em 1985, a revista

2. JM: as belotas lindas//JM comenta sobre os lindos olhos da menina//

3. IMC: É, os olhos, né? Quer tentar ler você?

4. JM: iajunha vozengrandi um lovomi lavaidi // e começa a rir//

5. IMC: Onde você tá, JM? // risos//

6. JM: beganho vojovanho que: um begão que begain um homem que gangangui vocerain vuci um bai mui:to bonita begain vojo bucão um bagão i e bagão e vogandi e vocrandi muito cândi

7. IMC: Credo, JM!

8. JM: Ave Maria! (COUDRY, 2003, p. 963).

${ }^{11}$ Maria Irma Hadler Coudry (2003) é representante da Neurolinguística Discursiva e Arpita Bose (2013) da Neuropsicologia Cognitiva, conforme mencionado. 
As marcações realizadas no recorte acima são iguais às apresentadas em Coudry (2003) e não há explicação ou justificativa para esses itálicos que aparecem em alguns pedaços da fala da paciente e nas significações que são demarcadas pelo investigador sobre a fala. $\mathrm{Na}$ análise original, esse fragmento aparece seguido de diversos outros e não é analisado individualmente, a discussão perpassa os processos de significação verbal e não verbal que devem ser realizados pelo investigador para o "bom caminho" dessa fala, e assume que "as dificuldades de produção dos sons da língua e dos gestos articulatórios se relacionam com a percepção: JM se beneficia do reconhecimento proprioceptivo" (COUDRY, 2003, p. 963).

Em uma releitura é possível observar que JM se apresenta com pseudo-palavras ${ }^{12}$ e, mesmo assim, a paciente prossegue (enunciados 4 e 6 , especialmente). Nessas sequências enunciativas, reconhecem-se palavras do português (em 6, "um homem que", por exemplo) e também fragmentos bem formados dessa língua, que se articulam formando pseudopalavras, mas dificilmente reconhecíveis ou admissíveis como neologismos porque não há palavra-referência para essas construções - elas não remetem a outras e não portam uma significação - exceção, talvez, de "begão", em 10, associado pela pesquisadora a "Afeganistão", provavelmente presente no texto lido ${ }^{13}$. Fato é que JM cede a iniciativa da interpretação à investigadora ${ }^{14}$ - ela escuta os abalos em sua fala e escuta a fala do outro ela $r i$ do que emerge em sua fala; diz "Ave Maria" depois de um "Credo" (essas palavras se convocam metonimicamente!); mas ela nada pode fazer para reformulá-las, corrigi-las, para dar prumo à sua fala (LIER-DeVITTO, 2003).

Vale destacar que o sofrimento nos leva a dizer que há escuta não alienada em muitos casos de afasia: há sujeito aprisionado numa fala sem direção, mas governada pela Língua. Segue a sequência paralelística do segmento citado:

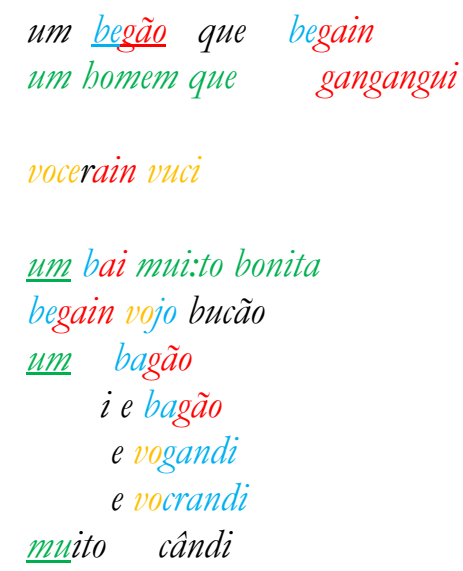

As cores utilizadas acima servem para mostrar o monta-desmonta-remonta estonteante da Língua em estruturas bem demarcadas (que foram anotadas, aqui, em paralelo). O sujeito afásico escuta, mas fica à mercê do que se compõe a partir dos movimentos da Língua (metafórico e metonímico) em torno de poucos elementos. $\mathrm{Na}$ verdade, "fragmentos" que não compõem uma fala aceitável, nem para o afásico. Fato é

\footnotetext{
${ }^{12}$ Essas pseudo-palavras são formadas por composições fonêmicas, silábicas, autorizadas pelo português, mas não formam palavras, nem neologismos (são irreconhecíveis como tal).

${ }^{13}$ Em Coudry (2003) há uma vinheta que antecede o dado explicando o contexto de leitura de um artigo de revista com o tema relacionado ao encontro de um jornalista com uma menina Afegã.

${ }^{14}$ Marcolino-Galli (2013) discute a função imaginária assumida pelo fonoaudiólogo para dar andamento à fala do outro, para "fazer falar".
} 
que ele fica não só à mercê da Língua, como também da interpretação do outro. Note-se que esta interpretação alternativa permite apontar para a hipótese do inconsciente. Ou ainda, em outras palavras, o sujeito mesmo que afetado pela escuta dos desarranjos de sua fala não consegue mudá-la, ele está aprisionado em sua própria língua e não no controle sobre ela, como propõe a afirmação da análise original desse dado.

É preciso deixar assinalar, porém, que há heterogeneidade - pode haver oscilações (comprovadas pela literatura e testemunhadas pela clínica) na escuta do afásico, como há para falantes não-afásicos. De todo modo e resumidamente, o segmento acima mostra um sujeito preso a pedaços sonoros que repetem e se contaminam, promovendo articulações significantes imprevisíveis e inaceitáveis como palavras do português (às vezes chegam perto, mas não chegam lá por vontade do falante). Esse jogo da linguagem sobre a linguagem nos mostra que há restrições na montagem da cadeia, no caso, restrições impostas pela sonoridade da língua (não semânticas ou discursivas) - as restrições são estruturais. Há, portanto, relativa “desordem”, mas não há caos porque há estrutura como disse Lacan, há uma ordem significante na cadeia falada.

Sendo assim, a jargonafasia não parece se encaixar nas descrições tradicionais de jargão que o remetem a falha no acesso lexical e semântico da língua, ou ainda, a sons sem significado e/ou conjunto de neologismos, parafasias e circunlóquios. Ela também não pode ser medida/quantificada pelas desordens que aparecem na fala do afásico. Mais interessante é chegar perto da dissociação profunda entre escuta e movimentos na fala. Interessa precisar a natureza de escuta "em sofrimento" e que "faz sofrer".

No segmento abaixo, também retirado da literatura fonoaudiológica, dessa vez de um artigo da Neuropsicologia Cognitiva, há diferença em relação ao dado anterior, mas a algo do mesmo:

I don't know...its semicurer...its big its...has no........no, no uh no...I do not know no...pigyburger...um...I don't know...I don't think there is...she has lugyburguer... she has radio... she has pigyburger pigyburger and uh blop...I guess there shoes and a spade...then if they were...but this bow is good nice to no...no...y I I think. (BOSE, 2013, p. 585).

Segue a sequência paralelística:

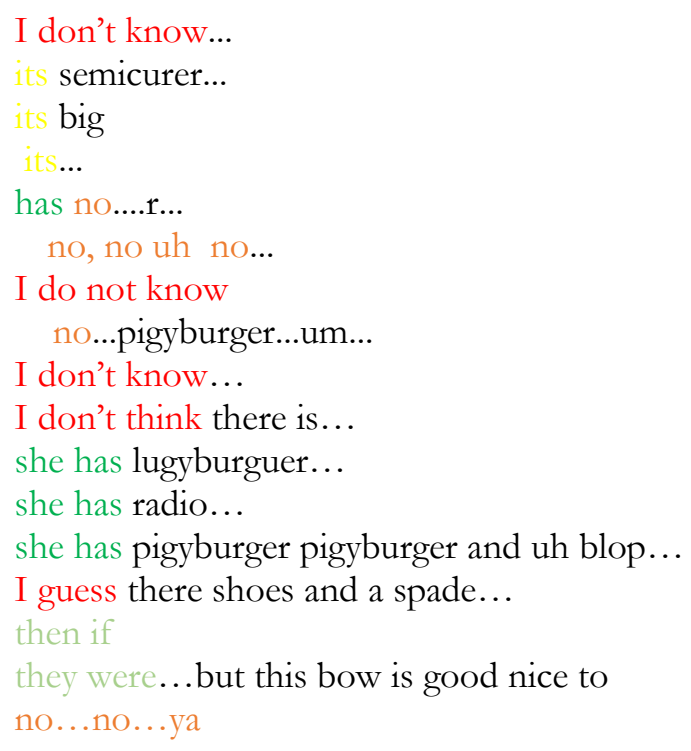


I think.

Bose (2013) não tem uma proposta de análise dialógica, esse dado é mencionado como exemplo de uma fala jargonafásica com presença de neologismos característicos de uma Afasia de Wernicke em uma atividade de descrição de figura sobre piquenique. Neste artigo são apresentados resultados em relação a provas de nomeação, repetição, compreensão, descrição de figuras, frisando a quantidade de neologismos. Ademais, o viés é descrever os processamentos cognitivos alterados para viabilizar um bom treinamento para o paciente.

Uma análise alternativa aponta para a força da estrutura - há menos desordem e um volume mais expressivo de pseudo-palavras (semicurer; pigyburger; lugyburger; blop; por exemplo). Observamos, contudo, sequências estruturais interrompidas, enunciados fracassados. Chama a atenção, ainda, as muitas pausas e hesitações - um falante mais presente na fala, mas, mesmo assim, derrotado na condução do que quer dizer (LACAN, 1956). Assiste-se, nos dois dados aqui apresentados, falas diferentes entre si, mas que têm em comum a força da Língua e o fracasso subjetivo. A heterogeneidade demanda uma resposta da clínica: cada situação é um caso, ainda que sinais sejam semelhantes (LIERDeVITTO; FONSECA, 2012, p. 77). Fato é que se "escutar-se é condição necessária e suficiente para engendrar reformulações numa fala dita "normal", ela não se apresenta como tal quando o que está em causa é a condição afásica" (LIER-DeVITTO; FONSECA, 2012, p. 77). Dilaceradora é a condição afásica para o sujeito, pois subverte toda sua relação anterior de falante com a língua materna, abala sua posição de falante - há sofrimento! $O$ afásico fica frente a um real ${ }^{15}$, que derrota esforços de reformulação, de fazer passar o sentido.

Importam também para esse momento da discussão algumas breves considerações sobre a interpretação na clínica de linguagem, afinal essa é uma das questões quando o que está em pauta são falas jargonafásicas. Está destacado na literatura e atestado pelo testemunho da clínica a dificuldade do outro para interpretar essas falas, como foi possível observar nos segmentos acima.

Lier-DeVitto e Arantes (1998) chamam a atenção para a noção de interpretação como restrição e para a relevância do outro, como "instância da língua constituída". Sendo assim, não podemos falar em uma clínica com informação psicológica sobre a subjetividade, que é, por definição, uma clínica da "compreensão", do significado. As autoras supracitadas sublinharam que se há "força estruturante da interpretação do outro" não é outra coisa que se deve esperar também numa clínica em que "o sentido não se define devido a um incessante deslocamento de fragmentos ao longo do texto" (LIERDeVITTO; ARANTES, 1998, p. 67). O que se suspende é a oferta do significado, embora o clínico, partindo da trama significante do afásico, recolha nela uma direção para uma construção imaginária, que possa, com a autorização do paciente, dar algum contorno e certa consistência ao diálogo clínico.

Pode-se afirmar que na interpretação ${ }^{16}$ de falas afásicas há algo de irremediável, de incorrigível, que lhe opõe resistência: um Real, nos termos psicanalíticos, que não se deixa apanhar no enlaçamento do Simbólico com o Imaginário de uma interpretação. Interpretação é restrição, contenção de deriva e certamente tem importância para

15 Para uma discussão sobre esse ponto ver Marcolino-Galli (2013).

16 O conceito de interpretação na Clínica de Linguagem foi trabalhado por Pollonio (2011) e Spina-DeCarvalho (2003). 
terapêutica, seu alcance varia de caso a caso. Interessa dizer que a interpretação na Clínica de Linguagem não é qualquer, tem especificidades e efeitos plurais e inesperados, que só se fazem notar no "só depois", como diria Freud, ainda que se trate de escuta especializada, instruída por uma teoria de linguagem.

\section{Considerações finais}

Apesar deste artigo não aprofundar a discussão de questões clínicas, é possível afirmar que as especificidades da fala jargonafásica levantam a seguinte questão: em que difere uma Clínica de Linguagem no atendimento de afásicos sem jargão e afásicos com jargão? Uma fala dita jargonafásica impõe desafios à escuta/interpretação do dito - isso é fato: distorções podem levar a uma espécie de derrisão da fala e da escuta. Mas é claro que os efeitos dessas falas são heterogêneos, afinal, podem produzir riso, choro, silêncio. Para além dos dados discutidos neste presente estudo, a prática clínica atesta que é importante ficar ao lado do sujeito e de seus movimentos para apreender o funcionamento linguístico na fala estilhaçada e acolher a demanda clínica de cada caso. Essa posição surtirá efeitos nesse sujeito, em alguma possibilidade de engate entre terapeuta e paciente, que favoreça diálogo e mudanças enunciativas. A especificidade da fala definida como jargonafásica não abala os pilares teórico-clínicos da Clínica de Linguagem com afásicos, o ponto é enfrentar a singularidade na clínica. Nessa direção, não está uma clínica que se guie por tipos clínicos. Não se toma partido de uma clínica para fala com jargões e neologismos, e outra clínica para uma fala com jargões e parafasias. Não se trata de desmerecer esforços descritivos e classificatórios, mas de sublinhar que eles não caminham na direção da clínica - estão mais a serviço dos ideais científicos de homogeneidade e previsibilidade, ideais que não beneficiam uma clínica em que a linguagem é protagonista (ARANTES, 2001; LIER-DeVITTTO, 2006).

Neste artigo, foi realizada uma aproximação particular de falas caracterizadas como jargonafásicas com o objetivo de iluminar seu funcionamento linguístico, reafirmando que há língua em pleno funcionamento na fala afásica. Além disso, destaca-se a importância para clínica de linguagem de uma escuta ${ }^{17}$ para o singular e para a sempre difícil posição do afásico frente à sua afasia. Ou seja, há uma impossibilidade de dissociar a análise da estrutura linguística subjacente à fala e a análise da escuta para a fala no campo da clínica.

Refletindo sobre os dados reinterpretados, é coerente retomar Lacan, que levantou questões sobre os neologismos na paranoia - manifestações também presentes na jargonafasia - é possível dizer que essas falas são repetitivas e um estorvo à significação; nesse sentido, elas são também "chumbo na malha, na rede do discurso do sujeito" (LACAN, 1956, p. 45). Contudo, não há comparação ou analogia possível entre falas afásicas e falas psicóticas - a condição subjetiva presente nesses quadros é profundamente diversa. Convém não reduzi-las a um mesmo - diferenças devem ser respeitadas, assim como foi postulado sobre fala de crianças. Aliás, é Lacan mesmo quem sublinha essa diferença, ao dizer que, no caso de afásicos, eles "ficam ao lado do que querem dizer". Diferença essencial, sem dúvida. E mais, o afásico "escuta", sofre, mas não pode "passar a outra coisa" (ALLOUCH, 1995), afinal, esta é a natureza de um sintoma.

\footnotetext{
17 O trabalho de Lier-DeVitto e Emendabili (2015) destaca a importância da escuta do fonoaudiólogo no instante clínico para produzir mudanças na fala dos pacientes - sendo a constituição de escuta singular para cada caso; essa dependerá da articulação da escuta no ato do instante e fora da cena, assim como já postulou Arantes (2001).
} 
O enfrentamento clínico de manifestações afásicas demanda a construção de uma escuta - da impregnação no corpo do clínico de uma teoria de linguagem. E não é por outra coisa que fonoaudiólogos são procurados: para emitir um dizer sobre o que acontece na fala do sujeito e para, nela, promover mudanças (possíveis). É possível, nesses termos, recolher o sujeito e sua fala estilhaçada. É possível colocar-se um tanto ao seu lado se o clínico suportar um "espaço de não saber", de "fora do sentido", frente ao efeito de estranho que decorre da concatenação desordenada, embaralhada e repetitiva de manifestações ditas jargonafásicas. Neologismos, estereotipias ou parafasias, características e descrições da literatura para essa manifestação, não definem adequadamente essas falas. As articulações significantes que emergem não são neologismos em sentido estrito - são mais pseudopalavras, cuja fonte ou matriz são, muitas vezes, ininterpretáveis. Ou seja, caminha-se em outro sentido daquele frequentemente definido pela literatura. A questão do paralelismo também deve ser destacada, já que se apresenta nos dois dados discutidos, portanto, seriam as falas jargonafásicas um aprisionamento de um sujeito em uma estrutura paralelística que põe em movimento um conjunto restrito de sons? Fato é que há presença marcante do paralelismo em falas jargonafásicas. Conclui-se afirmando que é fundamental incluir o "estranho" aí para discutir essas composições insólitas - um estranho que aprofunda o fosso entre falantes.

Essas considerações finais abrem espaço para uma ampla discussão e não esgotam as questões, que poderão ser exploradas em trabalhos futuros.

\section{Referências}

ALLOUCH, J. Letra a letra. Rio de Janeiro: Companhia de Freud, 1995.

ANDRADE, L. Ouvir e escutar na constituição da clínica de linguagem. 2003. Tese (Doutorado em Linguística Aplicada e Estudos da Linguagem) - Pontifícia Universidade Católica, São Paulo, 2003.

ANDRADE, L. Considerações sobre a escuta na Clínica de Linguagem. Caderno de Estudos Linguísticos, Campinas, v. 47, p. 167-174, 2005.

ARANTES, L. O fonoaudiólogo, este aprendiz de feiticeiro. In: LIER-DeVITTO, M. F. (org.). Fonoaudiologia: no sentido da linguagem. 2 ed. São Paulo: Cortez, 1997.

ARANTES, L. Diagnóstico e clínica de linguagem. 2001. Tese (Doutorado em Linguística Aplicada e Estudos da Linguagem) - Pontifícia Universidade Católica, São Paulo, 2001.

BOSE, A. Phonological therapy in jargon aphasia: effects on naming and neologisms. Internacional Journal of Language \& Communication Disorders, v. 48, p. 582-595, 2013.

BROWN, J. W. Case reports of semantic jargon. In: BROWN, J. W. (org.). Jargonaphasia. Nova Iorque: Academic Press, 1981.

BUTTERWORTH, B. Hesitation and the production of verbal paraphasias and neologisms in jargon aphasia. Brain and Language, v. 8, p. 133-161, 1979. 
CARVALHO, G. M. Erro de pessoa: levantamento de questões sobre o equívoco em aquisição da linguagem. 1995. Tese (Doutorado em Linguística) - Universidade Estadual de Campinas, Campinas, 1995.

CARVALHO, G. M. Questões sobre o deslocamento do investigador em aquisição de linguagem. Caderno de Estudos Linguísticos, Campinas, v. 47, p. 61-67, 2005.

CARVALHO, G. M. O erro em aquisição da linguagem: um impasse. In: LIER-DeVITTO, M. F.; ARANTES, L. (org.). Aquisição, patologias e clínica de linguagem. São Paulo: Educ; FAPESP, 2006, p. 63-78.

CHOMSKY, N. Language and problems of knowledge. Cambridge, MA: The MIT Press, 1988.

CORDEIRO, M. D. S. G.; MARCOLINO-GALLI, J. F.; LIER-DeVITTTO, M. F. Jargonafasia: impasses teóricos e clínicos. Anais do Simpósio Internacional de Letras e Linguística, 3. Uberlândia: EDUFU, 2013.

COUDRY, M. I. H. Ajustes morfológicos na jargonafasia: instabilidade e sistematização. Anais do $5^{\mathbf{0}}$ Encontro do Celsul, Curitiba, p. 962-969, 2003.

DE LEMOS, C. T. G. 1992. Los procesos metafóricos y metonímicos como mecanismos de cambio. Substratum, Barcelona, v. 1, 1992.

DE LEMOS, C. T. G. Native Speaker's intuitions and metalinguistic abilities: what do they have in common from the point of view of language acquisition? Caderno de Estudos Linguísticos, Campinas, v. 33, p. 5-14, jul./dez. 1997.

DE LEMOS, C. T. G. Das vicissitudes da fala da criança e de sua investigação. Cadernos de Estudos Linguísticos, Campinas, v. 42, p. 41-69, jan./jun. 2002.

FONSECA, S. C. Afasia: a fala em sofrimento. 1995. Dissertação (Mestrado em Linguística Aplicada e Estudos da Linguagem) - Pontifícia Universidade Católica, São Paulo, 1995.

FONSECA, S. C. O afásico na Clínica de Linguagem. 2002. Tese (Doutorado em Linguística Aplicada e Estudos da Linguagem) - Pontifícia Universidade Católica, São Paulo, 2002.

FONSECA, S. C. Afasia: fala em sofrimento que faz sofrer um sujeito. XVI Congresso Internacional de La Alfal. Obras colectivas de Humanidades. Alcalá de Henares: Universidad de Alcalá, 2011.

ISHARA, C. Jargonafasia e funcionamento da linguagem: aspectos fonológicos e morfológicos. Anais do $5^{\mathbf{0}}$ Encontro do Celsul, Curitiba, p. 328-335, 2003.

ISHARA, C. Marcas da língua na afasia: neologismos e parafasias. Estudos Linguísticos, v. XXXIII, p. 847-852, 2004. 
ISHARA, C. A classificação como obstáculo. In: COUDRY, M. I. H.; FREIRE, F. M. P.; ANDRADE, M. L. F.; SILVA, M. A. (org.). Caminhos da neurolinguística discursiva: teorização e práticas com a linguagem. São Paulo, Mercado de Letras, 2010.

JAKOBSON, R. Dois aspectos da linguagem e dois tipos de afasia. In: JAKOBSON, R. Linguística e comunicação. São Paulo: Cultrix, 1988.

KARMILOFF-SMITH, A. Self-organization and cognitive change. In: JOHNSON, H. (org.). Brain development and cognition: a reader. Oxford: Blanckwell, 1986.

KINSBOURNE, M.; WARRINGTON, E. K. Jargon aphasia. Neuropsychologia, v. 1, p. 27-37, 1963.

LACAN, J. Função e campo da fala e da linguagem na Psicanálise. In: LACAN, J. Escritos. Rio de Janeiro: Jorge Zahar, 1956.

LACAN, J. O Seminário, livro 3: as psicoses. Rio de Janeiro: Jorge Zahar, 2010.

LEMOS, M. T. A língua que me falta. Campinas: Mercado de Letras, 2002.

LIER-DeVITTO, M. F. Os monólogos da criança: “delírios da língua”. São Paulo: Educ, 1998.

LIER-DeVITTO, M. F. As margens da Linguística (Memorial de Concurso para professor titular). São Paulo: Pontifícia Universidade Católica, 2000.

LIER-DeVITTO, M. F. Sobre o sintoma: déficit de linguagem, efeito da fala no outro, ou ainda...? Letras de hoje, Porto Alegre, v. 36, p. 245- 253, 2001.

LIER-DeVITTO, M. F. Patologias da linguagem: subversão posta em ato. In: LEITE, N. (org.) Corpolinguagem: gestos e afetos. Campinas: Mercado de Letras, 2003, p. 233-246.

LIER-DeVITTO, M. F. Patologias da linguagem: sobre as "vicissitudes de falas sintomáticas". In: LIER-DeVITTO, M. F.; ARANTES, L. (org.). Aquisição, patologias e clínica de linguagem. São Paulo: Educ; FAPESP, 2006, p. 183-200.

LIER-DeVITTO, M. F.; ARANTES, L. Sobre os efeitos da fala da criança: da heterogeneidade desses efeitos. Letras de Hoje, Porto Alegre, v. 33, p. 65-71, 1998.

LIER-DeVITTO, M. F.; FONSECA, S. C. "Reformulação" ou "Ressignificação"? Caderno de Estudos Linguísticos, Campinas, v. 33, p. 51-60, jul./dez. 1997.

LIER-DeVITTO, M. F. Hesitações e pausas como ocorrências articuladas ao movimento de reformulação. Cadernos de Estudos Linguísticos, Campinas, v. 54, n. 1, p. 67-80, jan./jun. 2012.

LIER-DeVITTO, M. F.; EMENDABILI, M. Uma posição sobre a escuta na Clínica de Linguagem. Linguística, v. 31, n. 2, p. 73-82, 2015. 
MARCOLINO, J. A Clínica de Linguagem com afásicos: indagações sobre um atendimento. 2004. Dissertação (Mestrado em Linguística Aplicada e Estudos da Linguagem) - Pontifícia Universidade Católica, São Paulo, 2004.

MARCOLINO, J. A parafasia como sintoma na afasia. In: MANCOPES, R.; SANTANA, A. P. (org.). Perspectivas na clínica das afasias: o sujeito e o discurso. São Paulo: Livraria Santos Editora, 2009.

MARCOLINO-GALLI, J. A relação memória-linguagem nas demências: abrindo a caixa de Pandora. 2013. Tese (Doutorado em Linguística Aplicada e Estudos da Linguagem) - Pontifícia Universidade Católica, São Paulo, 2013.

MILNER, J-C. O amor da língua. Tradução: P. S. Souza-Júnior. Campinas: Editora da Unicamp, 2012.

OLIVEIRA, R. D.; MARCOLINO, J. Considerações sobre o jargão na clínica de linguagem com afásicos. Revista Distúrbios da Comunicação, v. 21, 2009.

ORTIZ, K. Z. (org.). Distúrbios neurológicos adquiridos: linguagem e cognição. 2 ed. São Paulo: Manole, 2010.

PETERS, A. The units of language acquisition. Nova Iorque: Cambridge University Press, 1983.

POLLONIO, C. F. Interpretação e escuta na Clínica de Linguagem. 2011. Tese (Doutorado em Linguística Aplicada e Estudos da Linguagem) - Pontifícia Universidade Católica, São Paulo, 2011.

SAUSSURE, F. Curso de Linguística Geral. Organizado por C. Bally e A. Sechehaye. 34 ed. São Paulo: Cultrix, 2012.

SPINA-DE-CARVALHO, D. C. Clínica de Linguagem: algumas considerações sobre interpretação. 2003. Dissertação (Mestrado em Linguística Aplicada e Estudos da Linguagem) - Pontifícia Universidade Católica, São Paulo, 2003.

TUBERO, A. L. Parafasia: o quiproquó das palavras. In: MORATO, E. M. (org.). A semiologia das afasias: perspectivas linguísticas. São Paulo: Cortez, 2010. 